\title{
Pretemporal Transcavernous Approach for Resection of an Orbito-Cavernous Oculomotor Schwannoma
}

\author{
Martin J. Rutkowski ${ }^{1}$ \\ ${ }^{1}$ Department of Neurosurgery, Medical College of Georgia at Augusta \\ University, Augusta, Georgia, United States \\ Address for correspondence Martin Rutkowski, MD, Department of \\ Neurosurgery, Medical College of Georgia at Augusta University, 1120 \\ 15th Street, BI 3088, Augusta, GA 30912, United States \\ J Neurol Surg B Skull Base 2022;83(suppl S3):e621-e622. \\ (e-mail: MRutkowski@augusta.edu).
}
Abstract
Keywords
- pterional
- oculomotor
- schwannoma
- cavernous sinus
- superior orbital fissure
- parasellar
- transcavernous

The following operative video demonstrates surgical tenets and nuances of the pretemporal transcavernous approach in an unusual case of a 33-year-old patient suffering new onset diplopia and a third nerve palsy due to an orbito-cavernous oculomotor schwannoma. Near total resection was accomplished through an extended pterional craniotomy with pretemporal transcavernous exposure of her lesion, resulting in resolution of her preoperative oculomotor palsy and visual dysfunction. When combined with extended pterional and modified frontotemporal orbitozygomatic approaches, the pretemporal transcavernous approach provides excellent surgical access to the parasellar region including the superior orbital fissure and cavernous sinus. Meticulous dissection and early identification of tissue planes, including cranial nerve and vascular anatomy, allows for safe removal of tumors arising in this region. The link to the video can be found at: https://youtu.be/EuIRTP7wWBQ.
Conflict of Interest

None declared.

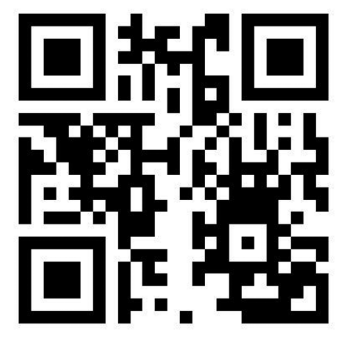

received

October 23, 2020

accepted

October 31, 2020

published online

April 8, 2021

www.thieme.com/skullbasevideos

www.thieme.com/jnlsbvideos

DOI https://doi.org/ 10.1055/s-0041-1724116. ISSN 2193-6331.

\footnotetext{
(C) 2021. The Author(s).

This is an open access article published by Thieme under the terms of the Creative Commons Attribution-NonDerivative-NonCommercial-License, permitting copying and reproduction so long as the original work is given appropriate credit. Contents may not be used for commercial purposes, or adapted, remixed, transformed or built upon. (https://creativecommons.org/ licenses/by-nc-nd/4.0/) Georg Thieme Verlag KG, Rüdigerstraße 14, 70469 Stuttgart, Germany
} 

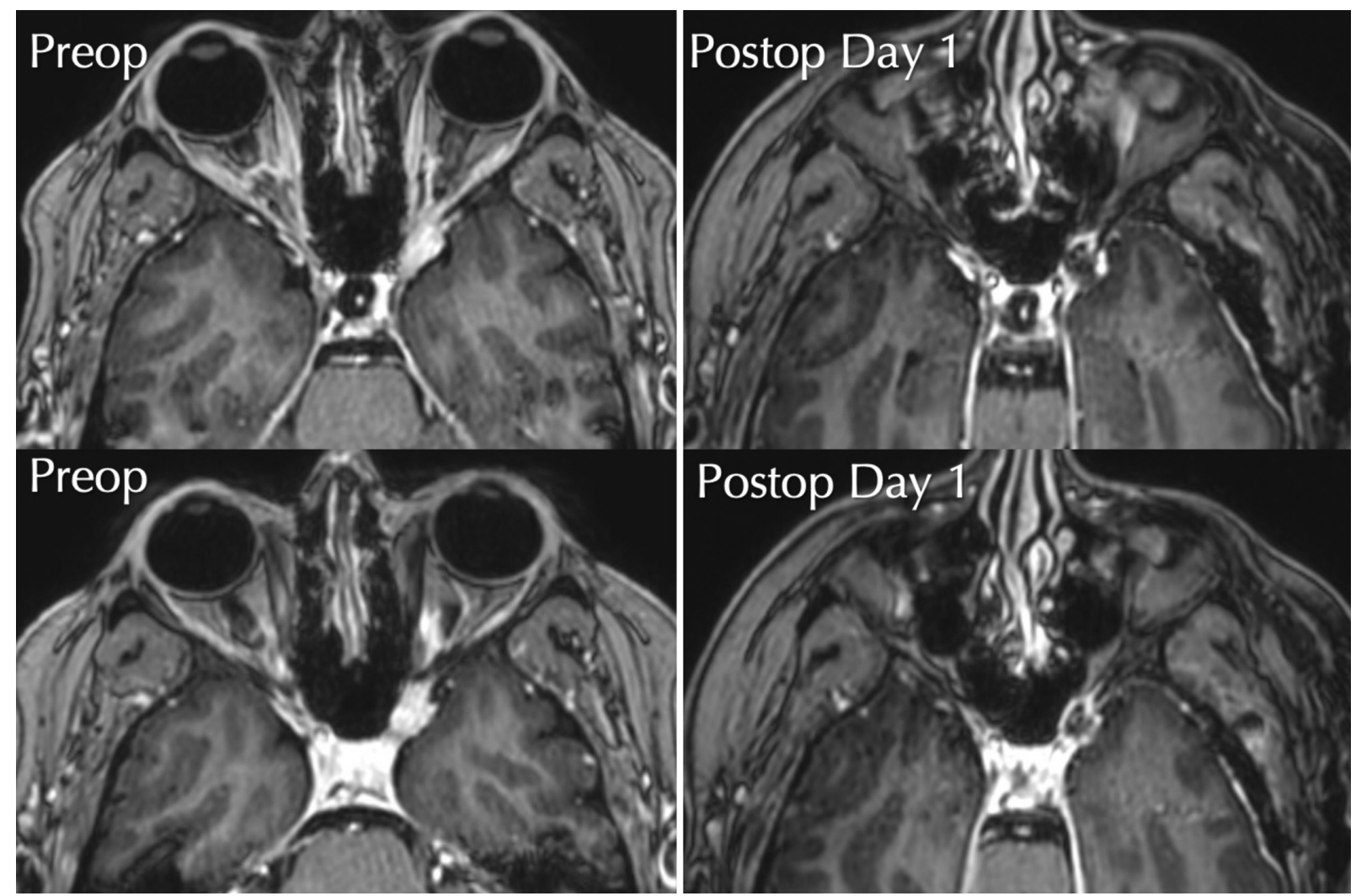

Fig. 1 Preoperative (left) postcontrast axial T1 magnetic resonance images demonstrating a homogeneously enhancing mass along the orbitocavernous portions of the left oculomotor nerve in a 33-year-old female patient presenting with sudden onset diplopia and third nerve palsy. Initial workup for inflammatory, vascular, and neoplastic lesions was unremarkable. The lesion was approached via a pretemporal transcavernous approach following pterional craniotomy. Postoperative (right) images demonstrate near total resection with preservation of the nerve fiber containing capsule.

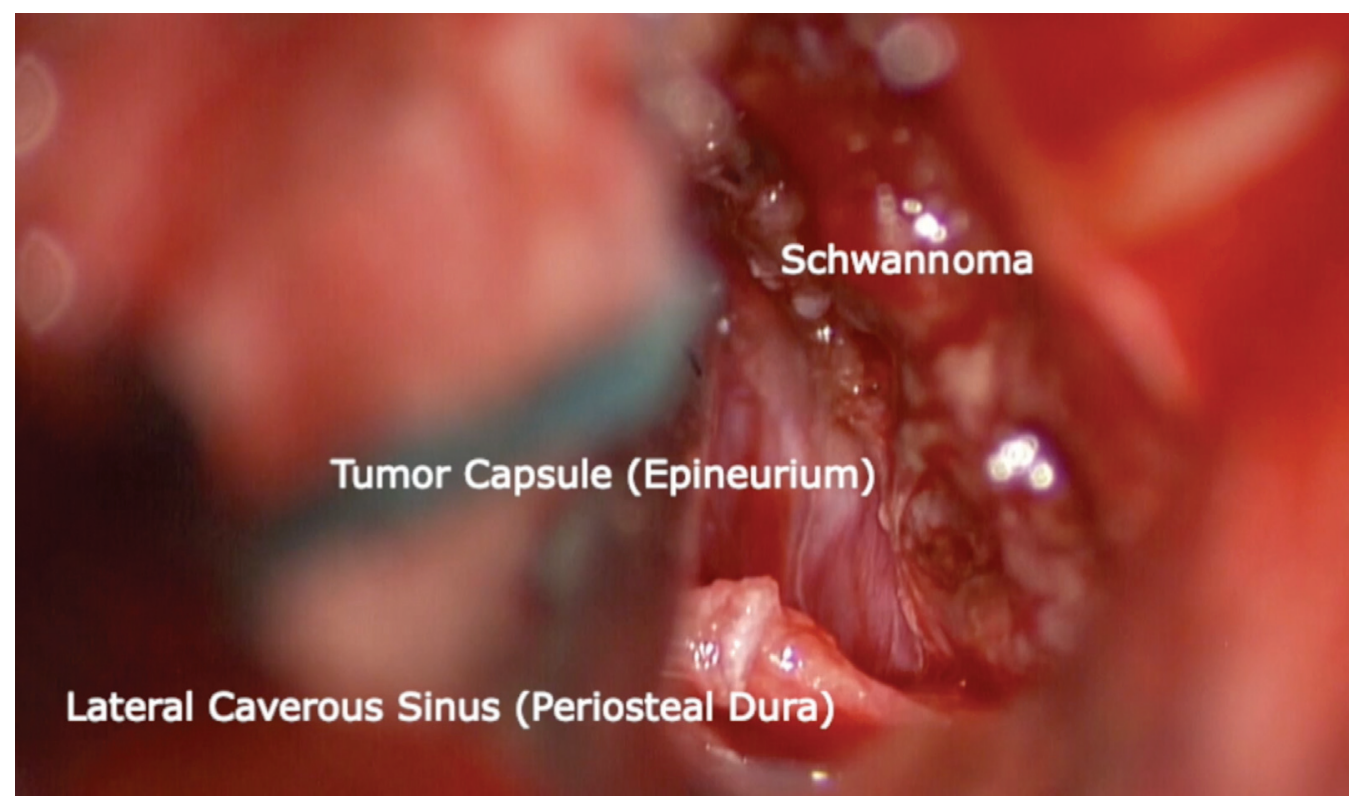

Fig. 2 Intraoperative image demonstrating the anatomic dissection planes used to safely resect the patient's oculomotor schwannoma. Following interdural dissection of the dura propria from the inner periosteal dural layer of the lateral cavernous sinus wall, the tumor capsule was identified without violating native oculomotor fibers. Development of the subcapsular plane allowed for aggressive resection while ensuring integrity of healthy nerve fibers. 